материалам Северной Бетпак-Далы). Алма-Ата: Гылым, 1992. 247 с.

13. Марьяшев А.Н., Горячев А.А. Вопросы типологии и хронологии памятников эпохи бронзы $\mathrm{Ce}$ миречья // Российская археология. 1993. № 1. С. 5-19.

14. Аванесова Н.А. Культура пастушеских племен эпохи бронзы азиатской части СССР (по металлическим изделиям). Ташкент: Фан, 1991. 202 с.

15. Зданович Г.Б. Бронзовый век Урало-Казахстанских степей. Свердловск: Изд-во Уральского университета, 1988. 182 с.

\title{
ANCIENT ARCHAEOLOGICAL COMPLEXES OF SOUTHERN PART OF KHANTAU MOUNTAINS
}

(C) 2018

Goryachev Alexander Anatolievich, senior researcher of Urbanization and Nomadism Department Saraev Vladimir Vasilyevich, specialist of natural sciences of Urbanization and Nomadism Department A.Kh. Margulan Institute of Archaeology (Almaty, Republic of Kazakhstan)

Abstract. The paper introduces new materials about archaeological monuments of the paleometal period and early nomads of the Khantau Mountains into scientific circulation. This region is the main one in the communication processes among the ancient population of the Central Kazakhstan steppes and the foothill areas of all North Tien Shan and Jetysu in particular. The southwestern slopes and the southern part of the Khantau Mountains were explored by the expedition of Archaeology Institute named after A.Kh. Margulan in 2017-2018, where series of ancient settlements, burial grounds and petroglyphs of the Bronze Age and the Early Iron Age were discovered. The materials of archaeological complex Kojabala show patterns of settlements location and burial grounds, which reflect the tradition of economic and cultural development of the region in Ancient times. We can associate the origin and existence of Kojabala-I burial with the process of Andronovo community Fedorovsky tribal groups migration from Central Kazakhstan in the XV and at the turn of the XIV-XIII centuries BC. The Bronze Age Kojabala tract materials analysis let us to assume, that economic and ethno-cultural intercourses of the population of Central Kazakhstan and Jetysu in this period were close. Such conclusion has perspective direction for further researches.

Keywords: Jetysu; Central Kazakhstan; Shu-Ile interfluves; South-West of Balkhash; Khantau mountains; steppe area; paleometal; Early Iron Age; settlement; stay; dwelling; housekeeping; burial mound; ancient mound; stone box; cyst; ceramics; bronze; burial rite; tradition.

УДК 902

Статья поступила в редакцию 15.02.2018

\section{ПОГРЕБЕНИЕ ПЕТРОВСКОЙ КУЛЬТУРЫ БЛИЗ СЕЛА ТАЛДЫ (КАРКАРАЛИНСКИЙ РАЙОН КАРАГАНДИНСКОЙ ОБЛАСТИ)}

(C) 2018

Кукушкин Игорь Алексеевич, кандидат исторических наук, ведущий научный сотрудник Сарыаркинского археологического института

Дмитриев Евгений Анатольевич, младший научный сотрудник Сарыаркинского археологического института

Кукушкин Алексей Игоревич, младший научный сотрудник Сарыаркинского археологического института Карагандинский государственный университет им. академика Е.А. Букетова

(2. Караганда, Республика Казахстан)

Аннотаичя. В рамках данной статьи публикуются результаты исследования случайно обнаруженного древнего захоронения у с. Талды (Центральный Казахстан). Сопроводительный инвентарь представлен металлическими кельтом-теслом, сильно фрагментированным браслетом с закрученным в спираль концом и керамическим сосудом с ребристым плечом и геометрическим орнаментом. Полученный материал позволяет отнести погребение к петровской культуре эпохи бронзы.

В вопросе терминологии авторы статьи исходят из слабой аргументации регионального аналога «петровки» - нуртайской культуры, выделенной в конце XX в. Имеющаяся на данный момент база источников характеризуется разнородностью, в связи с чем раннеандроновские древности Центрального Казахстана следует рассматривать в рамках петровской культуры, с возможным в дальнейшем выделением локального варианта или этапа.

Довольно интересен обнаруженный кельт-тесло, имеющий аналогии в памятниках Долгая Гора (абашевская культура), Танаберген II (синташтинская культура), Нураталды-1, Кеноткель XVIII (петровская культура) и Шайтанское Озеро II (коптяковская культура).

По формально-типологическим признакам известные экземпляры подразделены на два подтипа: ранний абашевско-синташтинский и поздний - петровско-коптяковский. Находка у Долгой Горы предполагает зарождение данного типа орудий в позднеабашевской культуре Приуралья.

Известные этнографические параллели позволяют установить, что изделия предназначались для обстругивания жердей, ошкуривания дерева, удаления сердцевины из заготовок и других работ, связанных с деревообработкой. 
Кукушкин И.А., Дмитриев Е.А., Кукушкин А.И.

Ключевые слова: Центральный Казахстан; эпоха бронзы; петровская культура; сейминско-турбинский феномен; коптяковская культура; синташтинская культура; абашевская культура; нуртайская культура; технология металлообработки; типология; случайная находка; желобчатый браслет; кельт-тесло; деревообработка.

В 2017 г. жителем с. Талды, Максатом Оспанкуловым, при добыче песка для строительных нужд обнаружено древнее погребение, о чем было сообщено в Центр по сохранению историко-культурного наследия Карагандинской области. На место находки оперативно выехала исследовательская группа, изучившая найденные материалы.

Памятник находится в Каркаралинском районе Карагандинской области, в 5 км юго-западнее с. Талды (бывший п. Фрунзе), возле грейдера. Погребение выявлено на глубине около 1 м (уровень залегания находок). Судя по отсутствию каменных конструкций, оно представляло собой грунтовую яму, ориентировку и размеры которой установить не представляется возможным. На дне были обнаружены человеческие останки, метаподия барана, металлические фрагментированный браслет с закрученным в спираль концом, кельт-тесло и керамический сосуд.

Сосуд имел горшечную форму, острое ребро по плечику, переходящее в плавно изогнутую шейку со скругленным отогнутым наружу венчиком, под которым нанесена цепочка наклонно заштрихованных ромбов. Ниже, между двумя каннелюрами, имеется узкий валик. В нижней части шейки изображены пирамидки. По ребру отмечены три каннелюры, под которыми нанесен трехрядный горизонтальный зигзаг, а придонная часть орнаментирована четырьмя каннелюрами. Рисунок на внешней поверхности горшка выполнен гладким штампом. С внутренней стороны сосуда, под венчиком, имеется желобок, над которым изображены наклонно заштрихованные равносторонние треугольники, нанесенные зубчатым штампом. Диаметр устья - 32 см, плеча - 33 см, дна - 13 см. Общая высота сосуда составила $23,5 \mathrm{~cm}$ (рис. 1: 1).

Кельт-тесло - имеет раскованный обух, края которого загнуты в несомкнутую втулку. Изделие плавно расширяется к слегка скругленному, заостренному лезвию. Длина орудия - 9 см. Втулка овальной формы, размерами $3 \times 2,5$ м. Максимальная ширина лезвия $-4,5$ см (рис. $1: 2$ ).

Фрагментированный браслет - желобчатый с закрученным в спираль окончанием в 5 оборотов. Диаметр окончания - 1,4 см, толщина до 0,25 см (рис. 1: 3).

Культурная принадлежность обнаруженного захоронения не вызывает сомнений - петровская культура эпохи бронзы, о чем свидетельствует керамический сосуд, который имеет ряд характерных признаков. Прежде всего, это ребро по плечику горшка, а также орнамент, выполненный по прямой сетке гладким штампом [1]. В конце XX в. А.А. Ткачевым была выделена нуртайская культура как центральноказахстанский аналог петровки, в которую вошли раннеалакульские памятники региона. Одними из особых признаков самостоятельности стали высокие пропорции сосудов, преобладание каменных ящиков [2]. Однако новые полевые исследования дали показательные материалы, подвергающие сомнению выделение новой таксономической единицы. Так, на могильниках Ащису, Сенкибай-2 и Кызылтау большинство захоронений совершено в крупных грунтовых ямах, часть которых укреплена срубом. Керами- ческая коллекция Кызылтау характеризуется приземистыми пропорциями, ярко выраженным ребром и резко изогнутым венчиком, однако имеются сосуды с позднепетровскими чертами [3, с. 13-16]. Таким образом, в настоящее время раннеандроновские памятники Центрального Казахстана следует рассматривать в рамках петровской культуры, но с возможным в дальнейшем выделением нуртайского локального варианта или этапа, так как, на наш взгляд, имеются различия среди исследованных памятников, однако пока неясно - территориального или хронологического порядка.

Желобчатые браслеты с закрученными в спираль концами известны в широком временном и территориальном диапазоне и характерны для петровской, алакульской и федоровской культурных традиций. Аналогичные талдинскому экземпляры обнаружены в Центральном Казахстане на могильниках Нуртай [4, с. 189 , рис. 69: 25, 26, 30, 31], Бозенген [4, с. 230, рис. 96: 28,35$]$. Такие украшения характеризуются, прежде всего, уплощенностью спиральных окончаний, в отличие от конических спиралей у федоровцев [5, с. 69].

Довольно интересен обнаруженный кельт-тесло с разомкнутой втулкой. На этом изделии можно остановиться более подробно, тем более что число известных ему аналогий невелико: Танаберген II [6, с. 29, рис. 9: 2], Кеноткель XVIII [7, с. 54, рис 5: 8], Нураталды-1 [8, фото 3; 9, рис. 2: 6], Долгая Гора [10, рис. 24: 4] и Шайтанское озеро II [11, рис. 1: 4]. Ниже приведено их подробное описание и условия нахождения.

Могильник Танаберген II. Кельт-тесло обнаружено в погребении 22 кургана 7: «По пропорциям и конфигурации лезвийная часть орудия практически ничем не отличается от обычных плоских топоровтесел. Однако способ крепления находки имеет существенные отличия, так как изделие снабжено разомкнутой втулкой, изготовленной путем расковки обушной части. Это предполагает вариант крепления к коленчатой рукояти, конструктивно сближающей орудие с кельтами» (рис. 2: 2) [6, с. 186].

Святилище Шайтанское Озеро II. Изделие имеет несомкнутую втулку и расширяется к скругленному заостренному рабочему краю. Длина -8 см, ширина лезвийной части -6 см. Втулка овальная, размерами $3 \times 2$ см. Результаты спектрального анализа: меднооловянный сплав с примесью мышьяка (рис. 2: 3) $[11$, с. 69 , рис. $1: 4 ; 12$, с. 183 , рис. $1: 5]$.

Клад у Долгой Горы. Изделие «... имеет необычное втульчатое крепление, а именно кованую несомкнутую цилиндрическую втулку. Это изделие как бы имитирует кельт, но не с литой, а кованой втулкой». О.В. Кузьмина отмечает, что сейминско-турбинские и абашевские экземпляры имеют близкие размеры, однако в целом они имеют одинаковые пропорции в отношении ширины лезвия к ширине пятки (втулки) - равно 1,1-1,9 [10, с. 89]. Длина орудия около 7,5 см, ширина лезвия - 2,4 см, размеры овальной втулки: 2,1 × 1,6 см (рис. 2: 1). Результаты спектрального анализа: медная основа с примесью мышьяка (3,7\%) [13, табл. IX (окончание)]. 

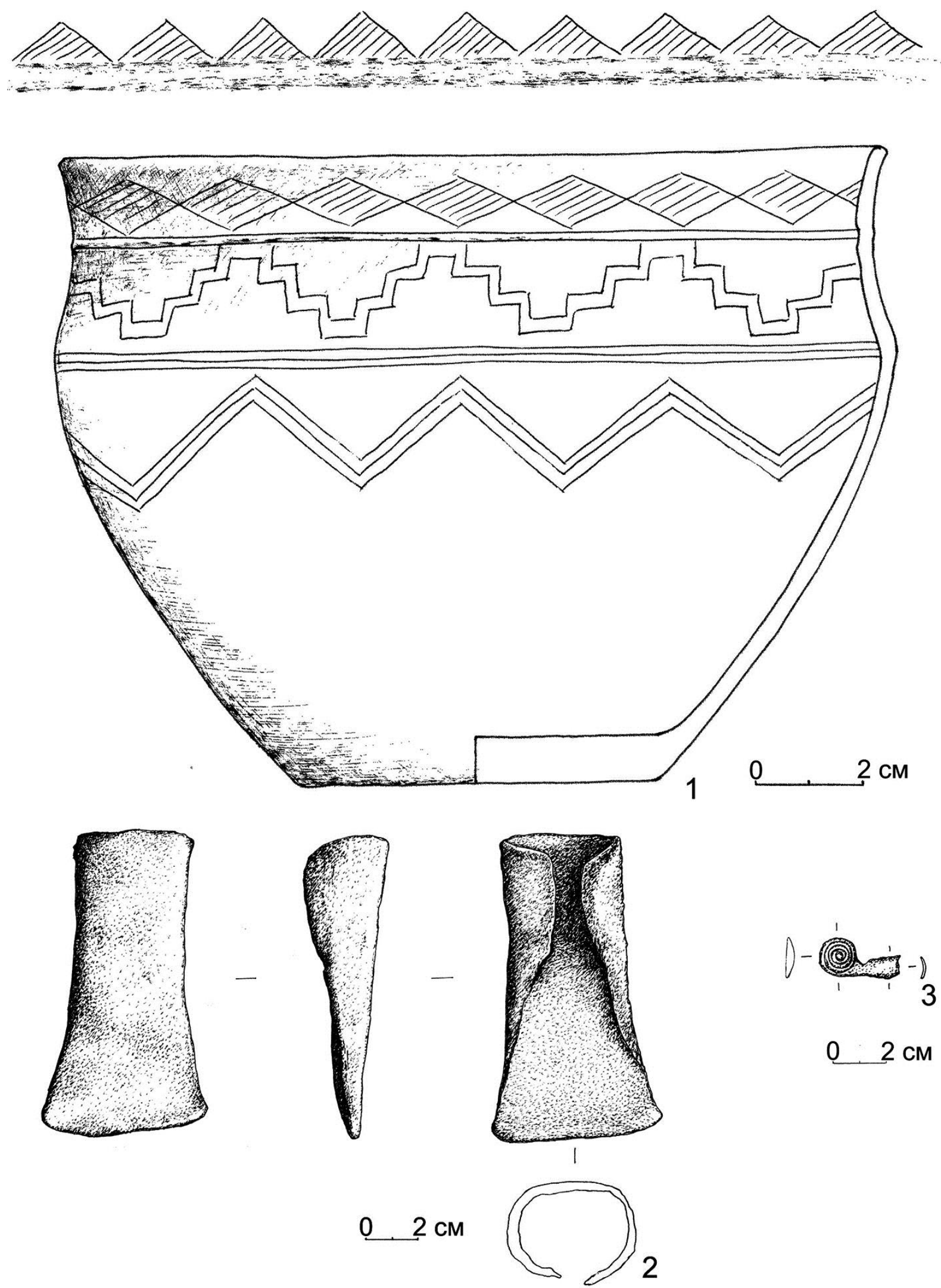

Рисунок 1 - Сопроводительный инвентарь из погребения у с. Талды.

1 - керамический сосуд; 2- металлический кельт-тесло;

3- фрагмент металлического браслета со спиральным окончанием

Могильник Кеноткель XVIII. Кельт-тесло обнаружено на дне могилы 1 и имеет несомкнутую втулку, в которой сохранились остатки дерева. Длина артефакта - 9,3 см, максимальная ширина лезвия - 5,3 см. Втулка овальная, размерами 3,2 × 2 см (рис. 2: 5) [7, с. 56].

Могильник Нураталды-1. Изделие имеет раскованную несомкнутую втулку. Длина кельта -10 см, максимальная ширина лезвийной части -6 см, втулка овальная в сечении, размерами $4 \times 2,5$ см. Рабочий край заострен. Обуховая часть раскована и загнута. Боковые грани загнуты и в виде закраин спускаются до рабочего края (рис. 2: 4) [9, с. 86]. Результаты рентгенфлуоресцентного анализа: медная основа с примесью олова $(7,06 \%)$. 

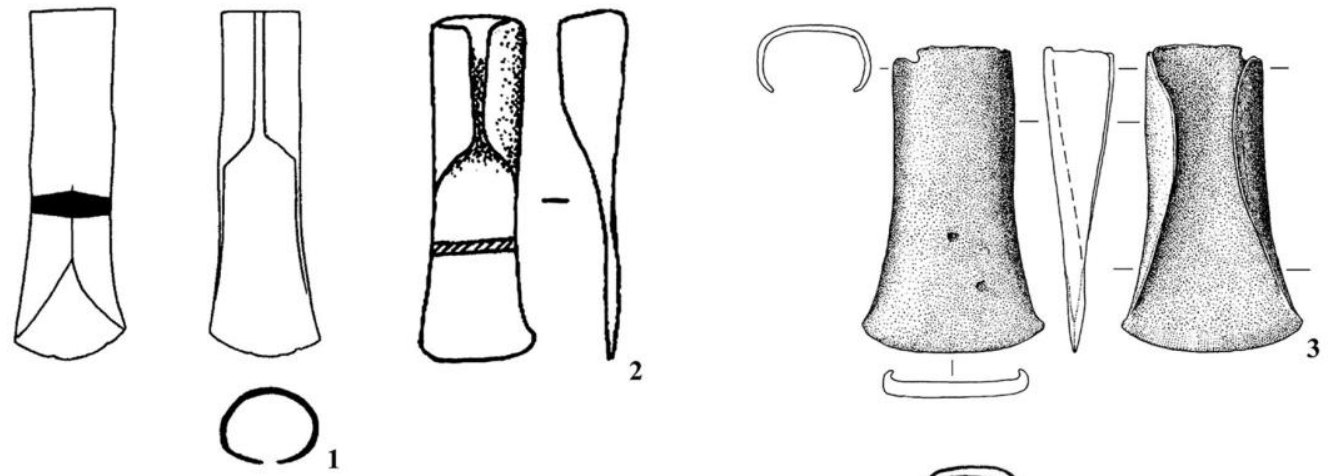

\section{2}
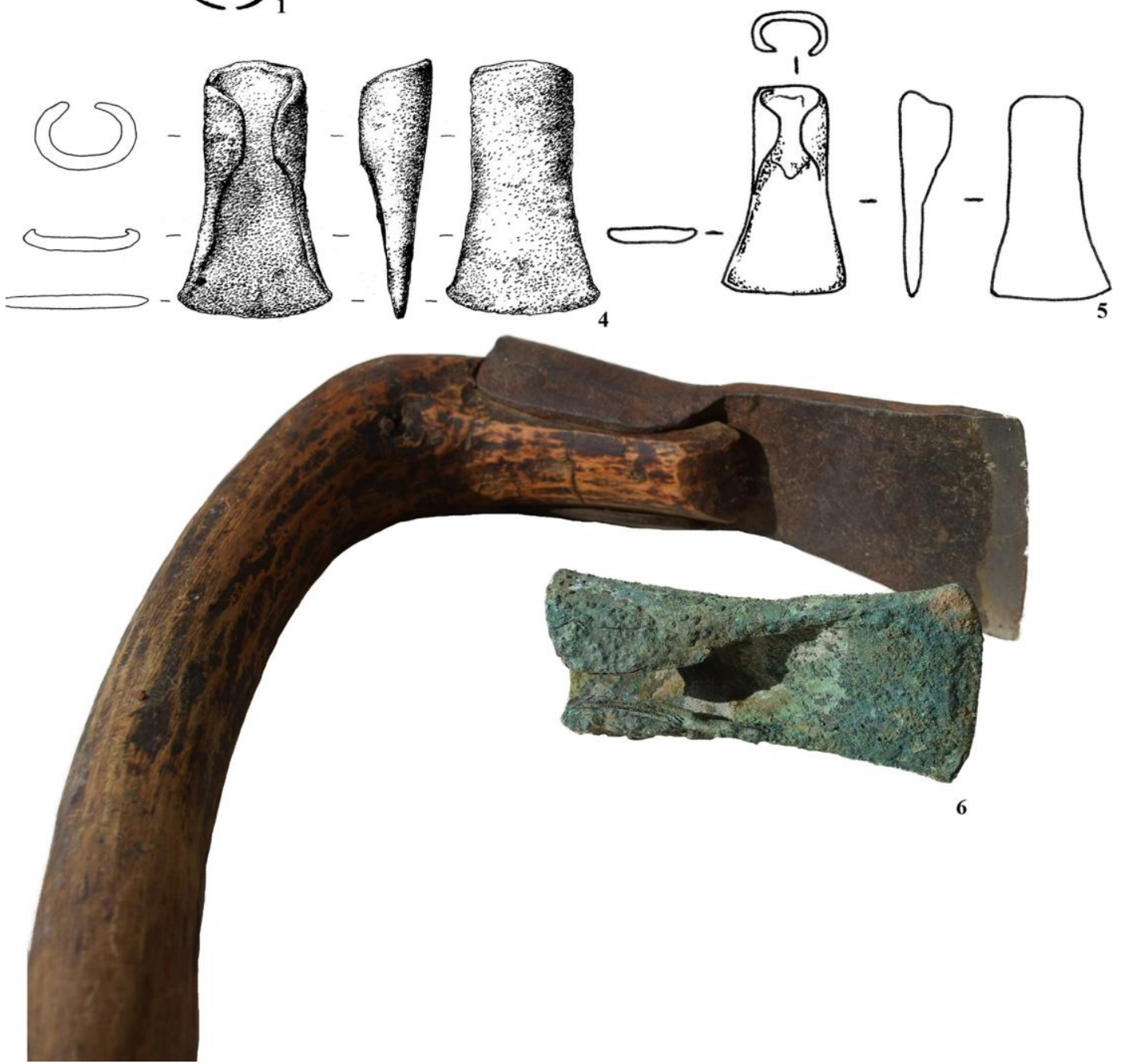

Рисунок 2 - Кельты-тесла бронзового века и их современный аналог.

1 - Клад у Долгой Горы; 2- Могильник Танаберген II; 3- Святилище Шайтанское Озеро II;

4- Могильник Нураталды-1; 5- Могильник Кеноткель XVIII; 6- кельт-тесло бронзового века из Талды и современный аналог орудия (предоставлен для сравнения жителем села Талды)

По формально-типологическим признакам кельты-тесла можно подразделить на 2 подтипа, основанием членения которых является уменьшение длины лезвийной части от ранних орудий, к более поздним в хронологическом плане экземплярам.

К 1-му подтипу принадлежат изделия из Долгой Горы и Танабергена II.

Согласно О.В. Кузьминой, клад у Долгой Горы относится к периоду завершения формирования абашевского культурного комплекса турбинского времени, который хронологически предшествует синташтинской культуре, формирующейся в результате трансформации позднего абашева [10, с. 65]. Однако в настоящее время нет серьезных оснований предполагать такой исторический сценарий культурогенеза синташты. Радиоуглеродные исследования показы- вают, что данные культуры в целом синхронны и датируются в рамках последней четверти III - первой четверти II тыс. до н.э. [14, с. 141]. Дополнительным аргументом является гетерогенность синташтинской популяции находившейся на стадии механического смешения, причем именно женские черепа несут черты уралоидного комплекса [15, с. 23-24].

Генезис кельта-тесла из Танабергена II, по мнению В.В. Ткачева, происходит в результате модификации плоского тесла под воздействием сейминскотурбинского восточного импульса, а находка у Долгой Горы предполагает зарождение этого типа в позднеабашевской культуре Приуралья [6, с. 283].

Необходимо отметить, что большое распространение изделия с несомкнутой втулкой получают в абашевской и синташтинской культурах. Сосуще- 
ствование на смежных территориях привело к освоению схожих принципов металлообработки, в том числе использование мышьяковой лигатуры [16, c. 255]. Технологический способ отковки рубящих орудий не характерен для сейминско-турбинских памятников, но и для всей свиты позднебронзовых культур лесной зоны Евразии, такой подход имеет корни в абашевской металлургии [17, с. 39].

Второй подтип появляется несколько позднее и получает распространение в памятниках петровской культуры (Кеноткель XVIII, Нураталды-1, Талды), датирующейся первой четвертью II тыс. до н.э. [14, c. 142], и характеризуется выработанной формой. Отливка изделия Нураталды-1 из медно-оловянной бронзы тенденциозна для петровцев, распространение которых на восток и южнее в районы Центрального Казахстана, приводит к переориентированию на местные залежи руды и использованию олова в качестве легирующего компонента, о чем свидетельствует, к примеру, анализ слитков металла [18].

Другая группа близких по форме кельтов-тесел известна на территории Восточного Казахстана [19, табл. X: 3, 4; 20, рис. 4: 17], однако орудия имеют литую сквозную втулку, которая маркирует иную технологию производства, подразумевающую использование сложных литейных форм. Принципы изготовления таких орудий лежат в недрах сейминско-турбинского феномена.

Дрейф традиции изготовления несомкнутых кельтов-тесел на север, в лесные районы, документируется по находке из святилища Шайтанское Озеро II, металлокомплекс которого сопряжен с керамикой коптяковского облика, но с некоторыми петровскими и алакульскими чертами на ряде экземплярах $[11$, с. 71$]$.

В вопросе функциональной атрибуции интересны этнографические параллели. Так, например, в казахских аулах до сих сохранились аналогичные по форме орудия (рис. 2: 6), которые применяются для обстругивания жердей, ошкуривания дерева, удаления сердцевины из заготовок деревянных изделий и других работ, связанных с деревообработкой.

\section{Список литературы:}

1. Зданович Г.Б. Основные характеристики петровских комплексов Урало-Казахстанских степей (к вопросу о выделении петровской культуры) // Бронзовый век степной полосы Урало-Иртышского междуречья. Челябинск: Башкирский государственный университет, 1983. С. 48-68.

2. Ткачев А.А. Особенности нуртайских комплексов Центрального Казахстана // Вестник археологии, антропологии и этнографии. 1999. № 2. С. 22-29.

3. Кукушкин И.А. Отчет о научно-исследовательской работе по теме «Исследование социально-стратифицированных погребальных комплексов Сарыарки в эпоху бронзы» (заключительный). Караганда, 2017. 121 с. Инв. № 0217РК00735.

4. Ткачев А.А. Центральный Казахстан в эпоху бронзы. Ч. 1. Тюмень: ТюмГНГУ, 2002. 289 с.

5. Аванесова Н.А. Культура пастушеских племен эпохи бронзы Азиатской части СССР. Ташкент: ФАН, 1991. 202 c.

6. Ткачёв В.В. Степи Южного Приуралья и Западного Казахстана на рубеже эпох средней и поздней бронзы. Актобе: Актюбинский областной центр истории, этнографии и археологии, 2007. 384 с.
7. Захаров С.В. Охранные археологические работы на могильнике Кеноткель XVIII в 2008 году // Маргулановские чтения - 2009. Петропавловск: Северо-Казахстанский государственный университет имени М. Козыбаева, 2009. С. 52-54.

8. Кукушкин А.И., Дмитриев Е.А., Шохатаев О.С., Елибаев Т.А., Бейсембаев Е.Е. Проведение научноархеологических исследований комплекса Нураталды (результаты полевых работ) // Сарыарқаның тарихы мен археологиясы. Қарағанды: Tengri Ltd, 2015. C. $37-48$.

9. Кукушкин И.А., Ломан В.Г., Кукушкин А.И., Дмитриев Е.А. Погребение с металлическим сосудом в могильнике Нураталды-1 (эпоха бронзы) // Уральский исторический вестник. 2016. № 4 (53). С. 85-92.

10. Кузьмина О.В. Металлические изделия и вопросы относительной хронологии абашевской культуры // Древние общества юга Восточной Европы в эпоху палеометалла (ранние комплексные общества и вопросы культурной трансформации). СПб.: Европейский Дом, 2000. С. 65-134.

11. Корочкова О.Н., Спиридонов И.А. Степные знаки в металле святилища Шайтанское Озеро II // Уральский исторический вестник. 2016. № 4 (53). C. $68-76$.

12. Корочкова О.Н., Спиридонов И.А. Степные знаки в металлическом собрании святилища Шайтанское Озеро II // Археологическое наследие Центрального Казахстана: сохранение и изучение: сб. науч. ст., посв. 70-летию организации ЦентральноКазахстанской археологической экспедиции Академии наук Казахстана. Т. 2. Алматы: Научно-исследовательский центр истории и археологии «БегазыТасмола», 2017. С. 182-187.

13. Черных Е.Н. Древнейшая металлургия Урала и Поволжья. М.: Наука, 1970. 180 с.

14. Молодин В.И., Епимахов А.В., Марченко Ж.В. Радиоуглеродная хронология культур эпохи бронзы Урала и юга Западной Сибири: принципы и подходы, достижения и проблемы // Вестник Новосибирского государственного университета. Серия: История, филология. 2014. Т. 13, вып. 3: Археология и этнография. С. 136-167.

15. Китов Е.П. Палеоантропология населения Южного Урала эпохи бронзы: автореф. дис. ... канд. ист. наук. М., 2011. 26 с.

16. Григорьев С.А. Металлургическое производство в Северной Евразии в эпоху бронзы. Челябинск: Цицеро, 2013. 660 с.

17. Черных Е.Н., Кузьминых С.В. Древняя металлургия Северной Евразии (сейминско-турбинский феномен). М.: Наука, 1989. 320 с.

18. Дегтярева А.Д. Слитки цветного металла петровской культуры (состав и технология получения) // Вестник археологии, антропологии и этнографии. 2015. № 2 (29). С. 38-50.

19. Черников С.С. Восточный Казахстан в эпоху бронзы // Материалы и исследования по археологии СССР. М.-Л.: Изд-во АН СССР, 1960. № 88. 272 с.

20. Агапов С.А., Дегтярева А.Д., Кузьминых С.В. Металлопроизводство восточной зоны общности культур валиковой керамики // Вестник археологии антропологии и этнографии. 2012. № 3 (18). С. 44-59.

Статья публикуется при поддержке гранта МОН РК АР05131774 «Исследование этнокультурных процессов на территории Сарыарки и сопредельных регионов в эпоху бронзы». 


\section{PETROV CULTURE BURIAL SITE NEAR THE VILLAGE OF TALDY (KARKARALINSK DISTRICT, KARAGANDA REGION)}

(C) 2018

Kukushkin Igor Alekseevich, candidate of historical sciences, leading researcher of Saryarka Archaeological Institute

Dmitriev Evgeniy Anatolievich, junior researcher of Saryarka Archaeological Institute

Kukushkin Alexei Igorevich, junior researcher of Saryarka Archaeological Institute Buketov Karaganda State University (Karaganda, Republic of Kazakhstan)

Abstract. The following paper contains investigation results of the randomly discovered ancient burial site near the village of Taldy (Central Kazakhstan). Accompanying inventory is represented by metal celt-adze, a highly fragmented bracelet with a spiral wound end and a ceramic vessel with a ribbed shoulder and geometric ornament. The obtained material allows attributing the burial site to the Petrov culture of the Bronze Age. The authors of the paper proceed from the weak argumentation of the regional analogue of «Petrovka», the Nurtai culture singled out at the end of the $20^{\text {th }}$ century. The current base of sources is characterized by heterogeneity. In this connection, the early Andronian antiquities of Central Kazakhstan should be considered within the framework of the Petrov culture with the possible further allocation of a local variant or stage. Celt-adze found here is quite interesting. It has analogies with the Dolgaya Gora monuments findings (Abashevskaya culture), Tanabergen II (Sintashta culture), Nurataldy-1, Kenotkel XVIII (Petrov culture) and Shaitan Lake II (Koptyakovskaya culture). According to the formal and typological features, the specimens found are divided into two subtypes: the early one - Abashev-Sintashta and the later one - Petrovsky-Koptyakovsky. The Dolgaya Gora finding presupposes the birth of this type of tools in the late Abashev culture of the Urals. The well-known ethnographic parallels allow us to establish that the products were intended for straining poles, sanding the tree, removing the core from blanks and other works related to woodworking.

Keywords: Central Kazakhstan; Bronze Age; Petrov culture; Seiminsk-turbinsk phenomenon; Koptyakovskaya culture; Sintashta culture; Abashevskaya culture; Nurtai culture; metalworking technology; typology; random finding; grooved bracelet; celt-adzo; woodworking.

\section{СЛУЧАЙНЫЕ НАХОДКИ ДРЕВНОСТЕЙ НА ТЕРРИТОРИИ САМАРСКОЙ ГУБЕРНИИ ВО ВТОРОЙ ПОЛОВИНЕ ХІХ - НАЧАЛЕ ХХ ВЕКА}

(C) 2018

Писарева Олеся Константиновна, магистрант кафедры отечественной истории и археологии Самарский государственный соииально-педагогический университет (2. Самара, Российская Федераиия)

Аннотащия. В статье впервые собрана разрозненная информация о случайных археологических находках и грабительских раскопках на территории Самарской губернии середины XIX - начала XX вв. Отмечается, что процесс археологического изучения Самарской губернии в дореволюционный период до сих пор остается неизученным. По итогам работы был составлен хронологический свод случайных археологических находок и раскопок, произведенных на территории Самарской губернии во второй половине XIX - начале XX вв. В состав свода включены все выявленные в процессе исследования факты обнаружения археологических памятников и отдельных артефактов с указанием времени и места обнаружения и состава находки или клада. За вторую половину XIX - начало XX вв., по данным источников, было выявлено 142 свидетельства о найденных древностях. Клады монет, украшения, предметы быта, предметы культа и прочие находки оседали в научных организациях и музеях Санкт-Петербурга, Москвы, Казани, Самары, Саратова и Симбирска. Многие находки утрачены, либо их судьба остается неизвестной. Вопросы, затрагиваемые в статье, неразрывно связаны с проблемой учета и охраны археологических памятников, сохранения культурного наследия.

Ключевые слова: археология; охрана культурного наследия; Самарская губерния; Императорская Археологическая комиссия; П.В. Алабин; памятники археологии; свод находок; клады; археологические раскопки; случайные находки; XIX-XX вв.; предметы культа; курганы; каменные статуи; Публичный музей; самарский губернатор.

Интерес общества к предметам древности был во все времена, но у отдельных людей он проявляется по-разному. Вокруг предметов древности складывались легенды и предания, далекие от истины. Находка клада считалась большой удачей: продав или переплавив его, можно было поправить свое материальное положение. «Волжские клады. Нигде, кажется, не сохранилось столько преданий о кладах, как в Самарской и смежной с ней Симбирской губерниях (правый берег Волги). Заговорите с тамошними крестьянами о кладах - и вам немедленно укажут десятки курганов, холмов и разных потаенных местечек, в которых схоронены клады Стеньки Разина. В некоторых местах мужики, как кроты, взрыли все окрест- ные холмы и курганы, но безрезультатно. Наоборот, случайные находки кладов наблюдаются чаще» $[1$, c. 130]. Жители российских деревень и сел постоянно наблюдали вокруг себя остатки старины, такие как курганы, валы, развалины древних сооружений и т.д. Нередко такие объекты подвергались разрушению в ходе грабительских раскопок, именно поэтому проблема учета и сохранения древностей как в XIX, так и в XXI веке обсуждается достаточно остро.

Актуальность темы заключается в том, что процесс археологического изучения Самарской губернии в дореволюционный период до сих пор остается неизученным. 